\title{
Components of the Physical Element of the Crime
}

\author{
Dr. Mohammad Mustafa Airout \\ Assistant Professor, Middle East University - Jordan
}

\begin{abstract}
This research sought to strengthen the jurisprudential and theoretical information on the concept of the physical element of crime and its elements which sharpens the legal knowledge of the researcher in the subject of research. It was not easy in this research to interrogate the researcher and put his own language in it because the subject matter of the physical element of the crime falls under the general theory of crime and under general provisions of the Jordanian Penal Code and this would put the researcher in the framework of a specific research in the language of jurisprudence and fixed theories and a precedent for scholars and legal evacuees. Since the physical element of the crime is based on three elements, namely the act (criminal behavior), the criminal result and causal relationship between them, this research has been divided into the following:
\end{abstract}

DOI: $10.7176 / \mathrm{JLPG} / 89-26$

Publication date:September $30^{\text {th }} 2019$

\section{Introduction}

It is not possible to imagine a crime without a physical element that expresses tangible materialism in the outside world that the penal legislator considered to be crimes according to specific legal provisions, the best evidence of the rule (no crime without a physical element). ${ }^{1}$

Stated in the text of the article (237/1) of the Code of Criminal Procedure No. 9 of 1961, which states:

(The decision includes a summary of the facts contained in the indictment and trial, the rule of law must include the legal article to which the act applies in the case of criminalization and the definition of punishment and civil obligations)

This text emphasizes that crime can only be achieved by an act of a material nature that touches the senses, and thus out of the circle of criminalization views, ideas and beliefs, which remain locked in the mind and are not expressed in any outward appearance of the law, where such views, ideas and beliefs are not subject to the penal legal framework because the criminal legislator does not hold people accountable for their conscience and conscience especially as it did not go out to the outside world, there has been no attack on the rights and interests of the community or its members.

Hence, it may be argued that the requirement of the physical element in the commission of the crime is a basic guarantee to prevent public authorities from infringing upon the security and fundamental freedoms of individuals, where these authorities are required to provide evidence and evidence of the occurrence of this physical element which is a key officer for not criminalizing individuals without legal evidence.

The jurisprudence combines the establishment of the physical element of the crime on three elements: The act or the criminal behavior, the criminal result and the causal relationship between the act or the criminal behavior and the criminal result. ${ }^{2}$

We must refer to the position of the Jordanian legislator in the Penal Code No. (16) of 1960 and its amendments from the physical element of the crime.

- The position of the Jordanian legislator in the Penal Code of the material pillar:

This research was not found in the text of the Penal Code A general text known as the physical element of crime, while the legislator identified the elements of the specific physical element of each crime when it appear in the section on crimes, but the Jordanian legislator mentioned in the third chapter of the third part of the Penal Code the subject (in the element of physical crime).

\section{Under this topic, the legislator dealt with the following sections: \\ 1. Initiate \\ 2. Sanctions meeting \\ 3. Publicity}

The conditions that must be provided to the material element of any crime is the appearance of a specific

\footnotetext{
${ }^{1}$ Husny, M. (1989) Explanation of the Penal Code, General Section, Issue,6., pp.271.

${ }^{2}$ Al-Majali,N. 2017 Explanation of the Penal Code General Department, Issue,6, pp. 251.

Al - Qahwaji, A. Explanation of the Penal Code General Department Edition 2008 Page (307).

Hosni, M. previous reference page 272 and beyond.

Ahmed, A. - Explanation of the Penal Code General Section, First Edition, 2012.

AL-Majali, N.Previous reference, P. 251 and beyond.

Al-Saeed, K. Explanation of general provisions in the Penal Code - 1998 edition, p. 203 and beyond.

Al-Kahwaji, A.- previous reference - page 309 and beyond.
} 
criminal act or conduct and the legislator may confine himself to this act or conduct to criminalize certain crimes, and may require the existence of a specific crime result in other crimes, then the causal relationship between the act and the criminal behavior must therefore be correlated with the criminal result and in both cases the offense is considered complete, but the offender may initiate a specific criminal activity and cannot complete his or her criminal activity or may be terminated without achieving the result of the crime that was intended, for a reason beyond his control, in this case he has not committed a full or complete offense, but the criminal offense is considered a punishable offense in accordance with the definition of the initiation contained in the text of article (68) of the Penal Code.

And because of the difference in the physical element in the complete crime, this research will be limited to the elements of the physical element of the complete crime.

\section{Chapter One \\ The Act \\ Introduction}

We have mentioned that there is no punishment for the thoughts that are in the mind of man and did not go out to external reality and did not affect the interests and rights protected by the law because the intention alone is not enough to criminalize and punishment. An act which is an element of the material element is the act punishable by law, there are acts that have not been punished by the legislator even if they fall within the preparatory process for committing the crime.

It seems that the Jordanian legislator considered that the preparatory work or just determination to commit the crime is not punishable, where the legislator in Article (69) of the Penal Code that it(Is not considered a crime just the determination to commit it and the preparatory work, anyone who proceeded to act and returned choice for the acts of procedural offense shall not be punished except for the act or acts committed by him if they constitute in themselves an offense).However, the legislator himself considered some preparatory acts as crimes in themselves for the seriousness of the activities involved,such as in article 107 of penalties, as well as the crime of criminal agreement contained in Article (157) penalties.

\section{What is the act}

The fuqaha ${ }^{1}$ 'have defined the act through a statement of its types, it was considered that the term act (Has a broad meaning, including positive behavior assumed movement of a member of the body of the offender, and it expands to refrain as a picture of human behavior, and then the legal terminology to call the refrain the expression of the negative verb and the act is an element in the physical element of the crime, whether deliberate or unintentional) $)^{2}$.

This research finds that the definition of a criminal act through a statement of quality:The positive and the negative act are closer to the truth than the general definition of what constitutes a "criminal act" or a "criminal behavior"because each type involves different elements to determine the legal framework, it is therefore not possible to establish a comprehensive definition that prevents this act of criminality in general.

One jurist has defined criminal behavior as ${ }^{3}$ being (Is the external physical activity of the offender to achieve the criminal result punishable by law, it is an essential element of every crime, the criminal legislator does not interfere with punishment before the external physical activity of the crime is created.

The study considers that such a definition of criminal conduct does not include an act of omission which involves the absence of any external physical activity but rather to leave or abstain from any particular physical activity which the law considers to be a legal and administrative duty.It would have been better to have a statement of the nature of the offense or criminal behavior through a statement of quality.

The Penal Code expressly provided for the two types of offense in the body of the article(92/1) Sanctions when referring to:

(Any person who commits an act or leaves harm shall be exempt from punishment when he did it he was incapable of realizing what his action or incapable of realizing his actions or he is incapable of knowing that he is prohibited from committing such an act or abandonment due to an imbalance in his mind).

So this chapter will be divided into the following two sections:

The first topic: negative action

The second topic: negative action (Refrain)

The first topic: positive action

\footnotetext{
${ }^{1}$ Hosni, M. previous reference page 272

Al Saeed, K. Previous reference page 204

Tawfiq,A. previous reference page 128 .

Al-Kahwaji, A. previous reference page 309

${ }^{2}$ Hosny, M. previous reference page 272.

${ }^{3} \mathrm{AL}-$ Majali previous reference page 254.
} 
Positive action or behavior is defined ${ }^{1}$ as:(A movement or administrative membership movements that would make a difference in the outside world, any significant change in the surrounding external entity it can be realized in any sense of the senses whether to leave physical traces sense of the word or not leave).

The affirmative action was also defined as: (voluntary membership movement) ${ }^{2}$

And from definitions of positive action that also:(An act which is prohibited by law, it is a voluntary membership movement of the offender). ${ }^{3}$

This research considers the positive act as: Tangible and concrete physical movements issued by the perpetrator through the organs of his body or other body affected by his physical action and express his will to realize the result of the crime envisaged).

This research consists of the above definitions that the positive action is based on two elements:

Organic movement and its will which will be presented by this research in the following two demands:

- The first requirement: organic movement

- The second requirement: the attribute

\section{The first requirement: organic movement}

\section{What is organic movement:-}

Represent voluntary movements in every tangible and significant physical expression to achieve certain material effects performed by the offender by a member of his body whether his hand or his leg or his head or tongue or uses his entire body examples include the use of the hand to hit, wound, hurt and kill, and use the head to hit, and the use of the tongue to denounce and mug and denigration and threat.

Organic movement can also take other forms such as a person using an irrational person or a trained animal for the purpose of carrying out the crime ${ }^{4}$, in such cases, the person is considered that he is the real perpetrator of the crime.

The Jordanian legislator considered as a public asset that the organic movement is composed of positive activity without entering into its composition a certain means or the place or time of this organic movement.

But an exception may be the form or means of organic movement a basic requirement in the legislator's view so that such organic movement is an element in the positive activity of the criminal. For example, the offense of fraud in article 417, this requires the use of fraudulent methods of fraud.

The importance of organic movement: -

The organic movement is the main component of positive action, where without it there is no positive action, therefore, there is no infringement of rights or interests, so do not imagine doing a positive act once determined, or determination to prejudice those rights or interests.

\section{The second requirement: voluntary character \\ What is the desired attribute}

Conscious and free will is the source and origin of organic movement, and at the same time is the vector or engine of organic movement, perceived will is that which drives the movement in a certain way or direction wanted by the member owner to achieve a certain goal, and this will(It controls and directs all parts of the organic movement in a certain way, and to clarify that all the materials that constitute the act must be coordinated in a particular direction drawn by the will and determine its features, thus, the voluntary orientation to all parts of the organic movement was an element of the will ${ }^{5}$.

\section{- The importance of voluntary character:}

It is easy to know the importance of voluntary character in the formation of positive action, if organic movements are stripped of their voluntary character there is no positive action and if these organic movements result in aggression or prejudice to certain rights and interests, and therefore do not carry out criminal responsibility.

Based on the foregoing, the following organic movements are not criminalized by the law:

First: the movements of membership issued by a person does not control his will on the members of his body and its example of losing consciousness while driving and causing physical damage to others.

Second: Membership movements issued by a person subject to material coercion loses complete control of the movement control of his members, for example, someone puts someone else's finger on the trigger of the gun and presses it, so the caliber goes off and hits another person. There may be a question of moral coercion, which falls on will and their impact on organic movement as a component of positive action.

\footnotetext{
${ }^{1} \mathrm{Al}$ - Kahwaji, A. previous reference, page 310

${ }^{2}$ Hosny, M. previous reference page 374 .

${ }^{3}$ Previous reference page 204.

${ }^{4}$ Tawfiq, A. Previous reference page 130

${ }^{5}$ Hosny, M. previous reference page 275.
} 
The coercion that falls on the will and if it leads to the lack of that will permanently, either through the loss of control of members due to malfunction or disease disruption of the will and its absence from reality or the presence of foreign control or external organs. However, the material coercion of its members makes them nonexistent but deviates from moral coercion which is on its direction, which distinguishes the organic movement qualities of will.

Although the result in the previous two cases is one in terms of the lack of criminal liability for organic movements that are excluded from their voluntary character however, the source of criminal liability is different in material coercion, reality on will is the source of irresponsibility is a lack of physical activity as a component of the physical element of the crime, while the moral coercion that paralyzes the will and lose choice be the source of irresponsibility is the failure of the criminal intent and the moral element of the crime.(It is worth mentioning that the will of the act is presumed, since it is always assumed that man does not produce an act except by his will, and that every act of human action is the source of free will, should be assigned to him and ask him, this means that the prosecution authority is not in a position to prove the existence of such free will, but this supposed Qurna is not conclusive in its significance, as it is accepted to prove the contrary, the accused may always prove by all means of proof that the thing that came to him was not born of free will) ${ }^{1}$.

\section{The second topic: - Negative action (Refrain) \\ Definition of negative action (Refrain):}

$\mathrm{Fiqh}^{2}$ is almost unanimous on one definition in view of the fundamental elements in which an act of abstinence or negative action must be available, where it is defined as the reluctance of a person to perform a certain positive action that the legislator expected from him under certain circumstances, provided that there is a legal duty required by this act, and to be able to refrain from giving it of his own will.

Based on the above definition, three elements can be drawn on which the negative act (Refrain) is to refrain from a certain positive action and to have a legal obligation to do so and the abstainer can do so voluntarily.

First: Refrain from doing a certain positive action: The process of refraining from a particular positive act is considered a negative position in relation to that act, and from this act the act of abstinence derives from its existence and its characteristics. But who determines the existence of this act and in what circumstances is required to do?

The legislature determines the existence of this act, and it also determines the existence of such circumstances, which are the primary source of the legislature's expectation that a person will submit a specific positive act or activity required by legal protection of interests and rights, if he does not perform such a positive act and in such circumstances he is considered to be abstaining from the point of view of the law.

\section{Second: Legal duty}

The second element of the act of abstinence or local activity is (The necessity of abstaining would violate a legal duty,because the criminal abstention assumes a legal obligation whether the source of this duty is the Penal Code or the laws supplementing it as the source of the duty may also have been legal such as a contract or general legal principles, such as the obligation imposed on each spouse by the other or requiring parents or guardians to care for their minor children). ${ }^{3}$

Third: the voluntary character of abstention.

The will cannot be separated from the passive act (Refrain) the abstention is considered a voluntary behavior, and if it is taken away from it, they will become non-criminal, and the free and chosen will must accompany the act of abstinence throughout the period of abstinence, but if a person loses free and chosen will during which he did the act of abstinence For reasons such as fainting or coercion, it is not considered abstinent.

(The voluntary character of abstention raises some difficulties for the crimes of "forgetfulness" which is crimes of non-intentional abstention) ${ }^{4}$ such as non-notification of a child within the period specified in the law, or not renew the license within the period specified for that purpose. These crimes are done by simply forgetting the offender to do the positive act imposed on him. The criterion of the average person shall be taken into account when judging in this matter who is in the same normal circumstances, in other words, just forgetting to do a legal duty is not a justification for abstaining under the pretext of the lack of will, as he loves the person to do the usual, to do his duty and not to forget, and this, of course, is quite different from cases of loss of will because of coercion, for example.

The Jordanian legislator cited the special section of the Penal Code applications for some crimes that occur by way of abstinence or negative action, article 206, for example, punishes anyone who is aware of a criminal agreement to commit an offense in the articles of (135-138) and Articles (142), (143), (145) and (148) and did not inform the public authority in a reasonable manner.As well as the crime of abstention by a police officer or

${ }^{1} \mathrm{Al}$ - Saeed, K. previous reference page 205

${ }^{2}$ Al-Majali, N.previous reference page 256,Hosny, M. previous reference page 276.

${ }^{3}$ Al-Majali, N.previous reference - p. 256

${ }^{4}$ Hosny, M. Previous reference - page 279,Al-Majali, N. Previous reference page 257. 
gendarmerie to comply with a legal request issued by the judicial or administrative authority in accordance with article 184 as well as what is stated in Article (332) which states:

(Punishable by imprisonment for a period not less than five years, the mother who caused (to prevent shame) by the act or intentional death of her child from the thief after his birth).

\section{Chapter Two \\ Result \\ Introduction}

The criminal result in criminal jurisprudence is known by highlighting its subjects.Physical significance and legal significance.According to these statements, questions are raised on the need for the availability of the criminal result for each crime or not,and the impact on the types of crime in terms of availability or lack of a criminal result.

So this chapter will be divided into the following two sections:

The first topic: Definition of the criminal result in their material meaning and legal meaning.

The second topic: The extent to which the criminal result is considered an element in the physical element of each crime.

The first topic: the criminal result in their physical and legal significance

This section will divide into two requirements: the first requirement, the material significance of the result, and the second requirement, the legal significance of the result.

\section{The first requirement: the material significance of the result}

The result is in accordance with its material concept (change and modification in the outside world as an effect of criminal conduct ${ }^{1}$ ), the external situation was in a certain way before this behavior was issued and then became another way after it was issued,the change from status to status is the result in its material sense. ${ }^{2}$

This research finds that the criminal result as a physical concept is purely physical phenomenon because it has a direct effect of the criminal activity,in the sense of the change that the actor in the outside world is doing by acting in the murder the victim was alive before the offender shot him,therefore, death is the effect (the criminal result) of an act or a criminal activity (shooting).

\section{The second requirement: the legal concept of the result}

The criminal result defined from the legal point of view(A violation of the right protected by the Penal Code,the result is aggression against the human right to life and aggression against the human right to the integrity of his body and aggression against the right of the owner of his property). ${ }^{3}$

It was also known as a legal idea (Aggression that affects an interest or a right as the street is estimated to be of criminal protection $)^{4}$

this research can define the criminal result in its legal sense as an attack on the rights and interests determined by the law to protect whether the Penal Code or other special laws or complementary. Regardless of whether those rights and interests are for individuals or for society as a whole.

This means that this presupposes the necessity of the report, beginning with whether the right or interest violated by the criminal offense is protected by law or not.

The second topic: The extent to which the criminal result is considered as an element in the physical element of each crime When taking into account the physical meaning of the crime, the existence of the criminal result is a fundamental element for the most crimes such as murder and theft, but in the few of them there is no need to be available for the completion of the physical corner, for example, simple negative crimes, where the legislator requires only negative behavior such as abstinence regardless of the effects that have been or have not been left behind by the non-performance of the certificate.

While if we define the result in its legal sense, it is an element in the physical element of each crime because the crime of criminalization the existence of infringement or aggression on rights protected by law, if there is no aggression, there is no criminalization.

As a result, the crimes are divided into two types:(Physical crimes are said to be(Crimes with result),Formal crimes are reported as such (Crimes of conduct and pure activity) ${ }^{5}$.

(The correspondence determined by the jurisprudence between physical crimes and formality crimes must be replaced by the correspondence between the crimes of harm and the crimes of danger). ${ }^{6}$ And the distinction between crimes of injury and risk crimes can be indicated by the fact that the damage offenses require actual damage while the criminal outcome of a risk-based crime as soon as the risk is available

\footnotetext{
${ }^{1} \mathrm{Al}$ - Majali, N. previous reference - Page 258.

${ }^{2}$ Hosny, M. Previous reference - page 280

${ }^{3}$ Al-Saeed, K.Previous reference - page 211

${ }^{4}$ Hosny, M. Previous reference page 281 .

${ }^{5}$ Hosny, M. Previous reference page 283

${ }^{6}$ Hosny, M. Previous reference page 283
} 
raises the possibility of harm by a threat to a legally protected right or interest.

\section{Chapter III \\ Causal relationship \\ - Definition of causal relationship and its importance:}

The relationship of causation is the link and the main link between the act of crime and the result of the crime, without them, no longer unity between the elements of the material element of the crime.

The causal relationship is a necessary condition for the unity of elements of the physical element in the crimes of damage but it is not the case for risk crimes that do not require the result of a harmful offense and the existence of the danger is limited to the possibility of a threat to a right of interest.

Therefore, the importance of the causal relationship as a major cause of criminal responsibility is important for criminal activity that occurs as a result of a harmful offense, if this relationship ceased and the crime was intentional the perpetrator is not asked for a complete crime but is asked to initiate it.

However, if an unintentional offense is not to be considered, the initiation is inconceivable in the unintentional offenses.

\section{Standard causal relationship:}

The intervention of other causes with the act of the actor in the creation of the harmful result in some cases may impose on criminal jurisprudence the development of the criterion of causal relationship.

Several doctrinal theories have arisen to determine the criterion of causality, and in general, these theories have been divided into two main directions:

- The first direction was based on a tie all the reasons which contributed to the harmful outcome of the crime in criminal responsibility, this trend is known as a theory of equal causes.

- The second trend was based on the different reasons that contributed to the creation of the harmful criminal result in criminal responsibility. The previous trends were defined in the following two sections:

1. Theory of equivalence of causes.

2. Theory of varying causes.

The first topic: - Equivalency Theory:

This theory is based on the idea that if there is more than one factor to produce the harmful result they are equal among themselves as a cause of the criminal result, regardless of the size of the perpetrator's contribution to that outcome whether a minor contribution or a significant contribution even if the other factors are dependent on the contribution of the offender.

In order to determine the causal relationship in accordance with this theory, it is necessary to answer this question:(Was the result that would have happened not for the conduct of the perpetrator?) ${ }^{1}$.

It is therefore possible to determine the availability of the causal relationship so that if the answer to the question is yes, it lists the right of the offender, if the answer is not, the causation relationship is terminated and the criminal responsibility of the perpetrator is not taken.

According to this theory, the reason for the equalization of the reasons is that without the act and behavior of the culprit, at the same time, the offender's act is also a reason for the existence of other factors causing the criminal result, an example of this is the shooting of the culprit on the victim who was admitted to the hospital and underwent an operation involving a medical error that led to his death,without the perpetrator doing what the second worker didthis theory has received many criticisms. Combine it with: ${ }^{2}-$

First, the theory of equivalence of reasons leads to the expansion of the circle of criminal responsibility, this would violate the rules of justice, which would be in the interests of society.

This criticism can be answered by the fact that there are other elements that must be met for criminal responsibility (the most important of which is the moral punishment of the crime) ${ }^{3}$.

Second: The theory of equivalence of reasons contradicts the provisions of the law that deal with the responsibility of the actor and partner.This criticism can be answered by the law and that there is a difference in the contribution of both the actor and the partner in the criminal act however, he equated them with the result of the crime and does not remove them (their causal value) ${ }^{4}$

In the face of these criticisms, proponents of a theory of similar causes have modified their concept so that the causation relationship becomes available if the conduct of the criminal offender is one of the factors necessary to produce the harmful criminal result or if the failure of such criminal conduct results in a modification of this finding $)^{5}$.

It is clear in this research that there is a difference between jurists in the effectiveness of the criterion

${ }^{1}$ Saleh, N. Lectures in the Penal Code - General Section - First Edition 1995 - Page 166

${ }^{2}$ Hosny, M. Previous reference - page 292

${ }^{3}$ Hosny, M. Previous reference - Page 292

${ }^{4} \mathrm{Al}$ - Majali, N. Previous reference - Page 267

${ }^{5}$ Saleh, N. Previous reference - page 167 
established by the equivalency Theory.

One of the jurists says (Despite this addition to the theory of equivalence of causes and they remain unfair because they make the perpetrator's conduct in the criminal outcome permanent, even if the effect is weak for the result of this result) ${ }^{1}$.

While another section of the jurists went to believe in the safety of the officer who was created by this theory for the causal relationship, indeed, this aspect of the jurisprudence goes in favor of the enforcement of this officer and to be adopted in a legislative and judicial manner, particularly in the area of intentional crimes ${ }^{2}$.

This research finds that the theory of equivalence of causes and their evaluation of the setting or selection of causal relationship, in accordance with its concept, which was developed and amended, in which it is fair enough to reach a just and fair judicial ruling.

Because the scrutiny and research by the subject judge in the statement of the necessary factors to create a harmful criminal result, and the assumption of the failure of the act of the actor and the perception of the outcome of the crime, the study sees this to some extent consistent with the theories of differing causes as illustrated in the subsequent demand.

The second subject: - The theory of differing causes

In fact, this theory involves the multiple causes of the result in several theories it is based on the distinction between the causative factors in producing the result of the crime and then the superiority of one over the other because it is responsible for the occurrence.

The most important of these three theories, the following theories: -

First: - Theory of the strongest reason: -

This theory is based on the search for the strongest cause for making the outcome of the crime, the standard of force here is not to compare the force of reason and other causes as a single unit, but rather to compare the strength of one cause and other reasons separately.

One of the most important criticisms faced by this theory is the absence of a clear, fixed and specific criterion for invoking the stronger reason, but they are contrary to the idea of criminal participation.

Second: The theory of the last reason.

This theory requires that the trial judge look for the causes of the crime and the latter is therefore the direct cause of the occurrence and to impose criminal responsibility for the occurrence of that criminal result.

This theory was criticized for leading to exemption the offender from punishment and criminal punishment because the trial judge will not hold criminal responsibility for those who committed criminal acts prior to the latter reason, and this in turn opposes the rules of justice because it leads to the punishment of a person who actually committed but was not the real cause of the outcome of the crime and what was his sin only if his activity was the last before the result.

Third: Theory of reason appropriate or adequate.

According to the proponents of this theory, the act of the offender is considered a cause of the criminal result if his action is sufficient alone to make them according to an objective criterion, which is the normal course of circumstances and normal events.

For example, a person fires on someone else's foot and when the person is taken to hospital, the ambulance overturns, resulting in the death of the injured person.According to this theory the person shooter does not ask for the result which is a person's death because his injury in his foot according to the physical course of the circumstances is not considered a fatal injury because it is not in the killing, however, this theory considered that the strength of its objective criterion (He is a normal person, average intelligence, caution ). ${ }^{3}$

After reviewing the most important theories that dealt with the criterion of causality relationship, it was imperative for this research to show the position of Jordanian legislation and justice on the criterion of causal relationship.

\section{The position of Jordanian legislation on causal relationship:}

The research reviewed the provisions of the Penal Code especially the general rules of articles (2-106) we did not find any reference or mention of any of the theories mentioned above only one legal provision is the text of article (345) which is reported under the title(Murder and victimization caused by multiple causes) in the first chapter of the eighth reason, this article stipulates that:(If death or victimization is intentionally caused as a result of critical reasons)or join a separate reason to do exactly. Punished as follows: -

1. Hard work for a period of not less than ten years if his work required the death penalty or life imprisonment with hard labor.

2. To reduce any other temporary penalty, even half of it, if it requires a penalty other than death or perpetual acts).

By analyzing this legal text, this study can produce the following results:

\footnotetext{
Al - Kahwaji, A. Previous reference - Page 327

${ }^{2}$ Al-Majali, N.Previous reference - Page 267

${ }^{3}$ Saleh, N.Previous reference - Page 170.
} 
First: - The Jordanian legislator avoid taking any theory of causal relationship theories, however, it specified the murder crimes and Intentional abuse with special provision relating to the causal relationship, and this special provision is based on the theory of equivalence of causes according to its old criterion, which is the equality of all the causes and factors that led to the result of the crime.

Second: The Jordanian legislator stipulated ignorance of the actor with advanced, accompanying or subsequent reasons for doing so. But this does not mean the interruption of the causality relationship if he knows those reasons, and this is governed by sound legal reasoning if the legislator punishes this actor despite his ignorance of the other reasons, it is first to punish him if he knows these reasons, and then it is not taken into account the reasons established by Article 345 of the Penal Code.

Third: - The legislator has stopped adopting any theory of the causal relationship to criminalize him for unintentional murder or abuse, and this is clear from the review of the text of the articles (343) and (344) of the Penal Code.

However, it should be noted that the legislator did not refer to the modern criterion of equivalence theory which is based on the assumption of the outcome of the offense in case of exclusion of the act of the actor.

\section{The position of the Jordanian judiciary on the causal relationship:}

Through a review of the decisions of the Jordanian Court of Cassation regarding the relationship of causation, he concluded the following results:

First: The Jordanian judiciary has stressed the adoption of the criterion of equal reasons in its meaning contained in the text of article 345 of the Penal Code, in the decision of the Court of Cassation No. 547/2007, Fifth Committee in History 4/6/2007 what is coming:

(The Jordanian legislator in Article 345 of the Penal Code resolved the issue of causation in homicides and the intentional harm to leave the offender's responsibility even if other independent factors have intervened, leading to a result which is the case of the mobile cause in this case of the disease of the former victim on a bullet wound and the cause of the added cause and that the death of the victim was due to the previous disease, a health condition for the victimrepresent the diseases that he suffers from and they constitute the underlying cause and that there is a causal link between the act of the accused and the underlying cause and the conditions of article 345 of the Penal Code are thus fulfilled, and that the intervention of the factors mentioned does not affect the description of the crime but is a reason to reduce the penalty of murder.)

Second: The Jordanian judiciary avoids what the Jordanian legislator has failed to take the criterion of modernity to the theory of equivalence of reasons where he took the criterion of non-responsibility of the actor for the outcome of the offense when it is certain that it will occur in the event of the absence of the act of this actor.

It came in the Jordanian Court of Cassation Decision No(1558/2006) a five-member committee on $13 / 3 / 2007$, the following:

(The Court of Cassation has been proceeding in the direction of equal reasons, in the sense that there must be a causal link between the act of the offender and the reasons and other factors that are unknown to the actor, which led to the death and so does not ask about this result when it was sure that it will deflate even if the attack did not occur.

See decisions of the Court of Cassation:-(330/2004 dated 19 April 2003) and No. 516/2004 of 30 June 2004 and No. 585/2005 dated 2 October 2005).

Third: The judgment of the Jordanian Court of Cassation was referred to in an old judicial decision No.(87/1975) (five body) published on page 641 of the number of the Journal of the Bar Association on 1/1/1976 to the criterion of causal relationship between mistakes and the result, Where this decision is as follows:

(The criterion in the availability of causality between error and result it is based on not imagining the occurrence of the result and to exclude error for the purposes of criminal liability, there is no difference between direct or indirect causation when the consequences are usually expected to be such an error.

* The driver who stands in the street to pick up a passenger which leads to the obstruction of traffic as his work could lead to accidents that lead to the deaths of passersby and passengers, especially if the incident is related to material facts as if at the dawn of a rainy day. Where vision is impaired and road traffic risks are increasing) and it is clear for the study from the extrapolation of the previous judgment that the Jordanian judiciary took the theory of the appropriate cause of the causal relationship, where we find that the judiciary took the standard of the average person in thinking and caution and circumspection at the same time, the presence of this person in the exceptional or normal circumstances of the normal course of things is taken care of, and this is the basis of the theory of the appropriate cause.

\section{Recommendations}

Through research into the elements of the physical element of the crime jurisprudence, legislation and judicial, this research concluded the following suggestions and recommendations:

First: It is better to amend the title of the third chapter of the third part of the Penal Code, which is entitled 
(in the element of physical crime) because the branches (1-3) below it are not associated with this title.

As these sections dealt respectively with the subject of initiation and the meeting of penalties, which are not related to elements of the physical element of the crime of the act and the result of the crime and causal relationship.

Second: The avoidance of the Jordanian judiciary not to adopt the modern standard theory of equivalence of reasons, when taken by the criterion of non-responsibility of the actor for the outcome of the offense when it is certain that it will occur in the event of the absence of the act of this actor, leads us to recommend that Article 345 of the Penal Code should be amended to add this standard on board.

Third: This research recommends that the legislator should not adopt any theory of causality where it must be left to the judge of the subject to invoke the causal relationship between the act and the criminal result according to the circumstances of each case displayed in front of him from the circumstances surrounding the act and the role of the actor in the outcome of the crime and according to the evolution of the means of committing crimes and their multiplicity.

\section{References}

Al-Majali, N. - Explanation of the Penal Code General Section - Dar Al-Thaqafa - Amman - Jordan - 6th Edition 2017.

Al - Saeed, K. - Explanation of general provisions in the Penal Code - House of Culture - Amman - Jordan 2010.

Hosni, M. - Explanation of the Penal Code - General Section - Department of Arab Renaissance - Cairo - 6th edition 1989.

Journal of the Jordanian Bar Association - included the provisions of the Jordanian Court of Cassation.

Kahwaji, A. - Explanation of the Penal Code - General Section - Halabi Rights - Beirut - edition 2008.

Saleh, N. - Lectures in the Penal Code General Department - Dar Al-Fikr - Amman - Jordan - First Edition 1995.

Tawfiq, A. - Explanation of the Penal Code - General Section - House of Culture - Amman - Jordan - First Edition 2011.

The electronic legal justice program has included the provisions of the Jordanian Court of Cassation.

\section{Sets of judgments}

Husni,M. Explanation of the Penal Code, General Section, 6th Edition 1989, pp. 271.

Al-Majali, N. Explanation of the Penal Code General Section, 6th Edition 2017, p. 251.

Al-Hakhuji, A. Explanation of the Penal Code - General Section - 2008 edition (307).

Hosni, M.Previous reference page 272 and beyond.

Ahmed, A. Explanation of the Penal Code - General Section, First Edition, 2012 Page 127.

Al-Majali, N.Previous reference, P. 251 and beyond.

Al-Saeed, K. Explanation of general provisions in the Penal Code - 1998 edition page 203 and beyond.

Al-Kahwaji, A. Previous reference - page 309 and beyond.

Husni,M.Previous reference page 272.

$\mathrm{Al}$ - Saeed, K.The previous reference. Page 204.

Ahmad, A.The previous reference. Page 128.

Al-Kahwaji, A.Previous reference, Page 309.

Husni,M.Previous reference page 272.

Al-Majali, N.Previous reference, Page 254.

$\mathrm{Al}$-Kahwaji, A.Previous reference page 310.

Husni,M.Previous reference .Page 374.

Al-Saeed, K.Previous reference, page 204.

Ahmed, A.Previous reference, page 130.

Husni,M. previous reference page 275.

$\mathrm{Al}$-Saeed, K.Previous reference page 205.

Al-Majali, N.op. Cit. Page 256,Dr. Mahmoud NaguibHosny, op. Cit. Page 276.

Al-Majali, N. previous reference - p. 256.

Husni,M.previous reference - Page 279 Dr. Nizam al-Majali - previous reference page 257.

Al-Majali, N.previous reference - Page 258.

Hosny,M.Previous reference - page 280

Al-Saeed, K.Previous reference - page 211.

Husni,M.previous reference page 281

Husni,M. previous reference page 283

Husni,M.- previous reference page 283.

Saleh, N.- Lectures in the Penal Code - General Section - First Edition 1995 - Page 166.

Husni,M. previous reference - Page 292 
Husni,M. previous reference - Page 292

Al-Majali, N. previous reference - Page 267.

Saleh, N.Previous reference - page 167.

$\mathrm{Al}$-Kahwaji, A.Previous reference - page 327

Al-Majali, N.previous reference - Page 267

Saleh, N.Previous reference - Page 170 